\title{
Research on the Novel Education Pattern for Science and Engineering Classes Based on Experiment and Interactive Teaching Method
}

\author{
Huang Wenzhun* \\ Department of Electronic Information Engineering \\ Xijing University \\ Xi' an, China \\ E-mail: huangwenzhun@xijing.edu.cn
}

\author{
Bian Wei \\ Academic Affairs office \\ Xijing University \\ Xi'an, China \\ E-mail:21443022@qq.com \\ * Corresponding Author
}

\author{
Xie Xinxin \\ Department of Electronic Information Engineering \\ Xijing University \\ Xi'an, China \\ E-mail: 346148500@qq.com
}

\author{
Zhang Hui \\ Academic Affairs office \\ Xijing University \\ Xi'an, China \\ E-mail: 52654708@qq.com
}

\begin{abstract}
In this paper, we conduct research on novel education pattern for science and engineering classes based on experiment and the interactive teaching method. Teaching ways should be further to the combination of knowledge and exploration, interaction between teachers and students teaching learning and to mobilize students' autonomous learning, stimulate student curiosity and creativity as the main goal of teaching way transformation. Classroom teaching is the main way for students to master basic theory, basic skills, to guarantee the quality of classroom teaching is in the classroom in the limited time and the space for the effective interaction of teachers and students. We believe that through a series of effective exploration and reform of teaching, it will usher in spring of higher education in the 21 st century. In this context, to develop high-tech talents with international level, we will break bondage of students thought the traditional education mode. The proposed experiment and the interactive teaching method enhance the overall performance of the education process which will be beneficial to optimize the current education pattern. In the future research, we will combine more corresponding theory into the topic to modify the current research result.
\end{abstract}

Keywords-Education Pattern; Science and Engineering; Experiment and Interactive; Teaching method; College Students

\section{INTRODUCTION}

In the face of prosperous development of electronic information technology and its related industries of electronic professional talents cultivation in the colleges and universities focus on application and neglected the foundation for a professional support. Electronic information special course teaching reform in the colleges and universities trend is to streamline the course content and periods, additional categories of the courses, strengthen the cultivation of students' practical ability and in the course of a minus one increases, the impact on the basic knowledge and influence should not be neglected, some teachers are prone to errors in the grasp of the course material, easy to guide to the streamline basics, expansion of breadth of knowledge, teaching content is wide and not pure, ignores the importance of the basic knowledge to students, this conflicts with solid talent training target. Electronic information special basic course is the theoretical basis and the practice as the foundation, the comprehensive training of students' knowledge, ability and quality plays a very important role, so the reform of the basic course of electronic and information profession in colleges and universities [1-2].

According to the literature reviews, the primary requirements for the information based majors can be summarized as the follows. (1) Electronic information technology in all fields of national economy has extensive applicability and permeability, the development of it, not only led to a new batch of the cross science and technology and emerging industry, has also created a new economic and the social needs. This requires us to cultivate a large number of the commands a wide-ranging knowledge based, open field of vision, achieve mastery through a comprehensive thinking ability, be familiar with the knowledge of different disciplines, have the ability to constantly adjust the structure of knowledge, that can adapt to continuous development of society and change of high-quality talent. (2) Electronic information industry for a long period of sustained high growth, making the total industry scale rapid expansion, the degree of commercialization, industrialization of new and high technology and much higher than the previous level and at the same time, the economy and the globalization of science and the technology, the interdependence between countries at the same time, competition is increasingly 
fierce. Rich and generous knowledge base, comprehensive solid basic skills, keen creative thinking and innovation consciousness, strong innovation ability form requisite to a knowledge economy era senior specialized talents and the formation and development of innovation ability is the systematic project. The formation and development of innovative ability in addition to innate factors, but also by day after tomorrow's environment, education, and practice factors such as the innovation of integrated decision process itself is a cognitive activity. The innovative thinking is the core. Its strengthening and development largely determine the success or failure gain and loss, and to cultivate college students' creative talents. With the continuous development of science and technology, the continuous renewal of teaching content, advanced instruments and equipment increased year by year, more and more high to the requirement of experimental team overall quality. Must have a contingent of teaching, scientific research and technical development strength of high level teaching team. This requires experimental technical personnel should not only love their own work, strong dedication and the primary sense of responsibility, must also follow closely the development of electronic technology, constantly learning new knowledge and new technology. The Fig. 1 shows the principles of the education pattern.

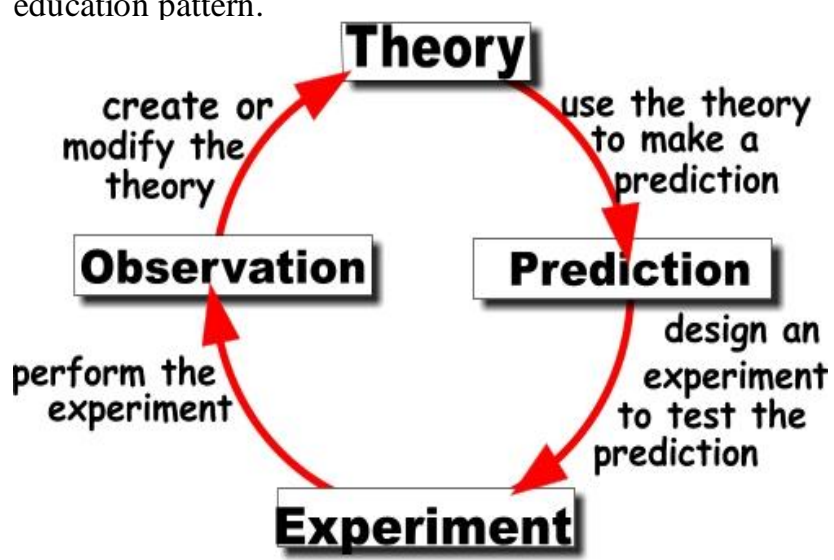

Figure 1. The Principles of the Experiment and Interactive Teaching Pattern

In this paper, we conduct research on novel education pattern for science and engineering classes based on experiment and interactive teaching method. Talented person's core competitiveness is the ability to innovate, create new scientific research and cultivate creative talents with innovation ability is always university bear unique task for the development of the society and the country, both makes exploration and create university never stopped working and goal. Under such a goal, whether to have continuous development change of educational concept and form new education methods and means to adapt to development of contemporary science and technology and the demand of social progress has become a problem of realization of creative talents training. In the following sub-sections, we will analyze the related issues in detail with theoretical discussion.

\section{OUR PROPOSED METHOdOLOGY}

\section{A. The Interactive Pedagogy}

Interactive teaching is under condition of modern education technology, through a certain situation, using a certain technology, methods, teachers and students communicate with each other, interaction, and so a kind of the teaching activity. It emphasizes that teaching is a teaching and learning of communication and the interaction, so as to realize teaching is learning and common development for the purpose, to mobilize students' learning enthusiasm, initiative, and fully reflect the personality of students to cultivate students' innovative thinking, innovative consciousness and innovative ability. Teaching skills refer to specific tips for teachers use various teaching methods, used correctly that can improve the effectiveness of teaching methods. Teaching skills are generally divided into language skills and language skills. Lecture logic will affect teaching content expression clarity and interesting and become the main aspects of language skills. Classroom teaching is the main way for students to master basic theory, basic skills, to guarantee the quality of classroom teaching is in the classroom in the limited time and space for the effective interaction of teachers and students.

- The language interaction. Classroom teaching between teachers and students to achieve real interaction, to adopt the way of "dialogue" communication. In the interactive relationship of the dialogue, the teacher to inspire the student through dialogue, guide students to find their knowledge and the wisdom. Attention should be paid to listen to the voices of students, give students some discussion time, make students' thinking is not limited to teachers' thinking and improve the general innovative ability of students [3].

- Emotional interaction. Teachers in teaching must fully mobilize students' learning enthusiasm and let students become passive to active learning. Let them experience the fun of learning, rather than to learn and learn. In this way, the teacher lectures just also have the enthusiasm, as infectious can attract students' attention as get active classroom atmosphere to promote the effectiveness of teaching, to guarantee the quality of teaching. For example, we can in class to tell everyone about this theory knowledge related case and in the case let everybody learn new concepts and the corresponding new operation [4].

Interactive teaching is the purpose of through effective teaching methods and measures, application of modern information technology, make the media combined with courses, construct interactive learning environment, through multimedia interactive interface to guide the student to obtain more comprehensive knowledge and ability. Make the design of the courseware and teaching objectives, teachers and students to form the overall interaction is illustrated and the combination of dynamic and static to attract the attention of the students. 


\section{B. The Experimental Didactics}

Task driven teaching method is derived from constructing doctrine teaching theory, traditional teaching will impart knowledge to solve problems and complete the task of multi-dimensional interactive teaching, task driven team teaching in the practice teaching activities designed a series of learning tasks, lets the student team together to complete freedom, under the drive of tasks become passive infusion to the active exploration so as to achieve better teaching effect.

Experiment teaching is to verify the theoretical knowledge, and skills training, training design and innovation spirit of important way especially for the electronic engineering. Project teaching method is a kind of typical student-centered teaching methods in the form of design, to complete the project to promote teaching process, to evaluate the teaching effect. Project information collection, the design and implementation, and evaluation are performed by the students as the main body as the teacher for help and guidance. Comprehensive experiment to enhance the students' enthusiasm and initiative, to strengthen the understanding of theoretical knowledge, to achieve the training skills and to develop the purpose of rigorous scientific attitude comprehensive experiment is organic blend of theoretical and experimental knowledge, to solve the complicated practical problems. This experiment aims to cultivate students' comprehensive ability to apply the knowledge to analyze and solve problems is the foundation of the design experiments. Comprehensive experiment is helpful for the students to form strong ability of self-study and independent work [5].

Project teaching method applied in electronic experimental course pattern design could be listed as the following aspects. (1) The choice of the project. This stage is mainly completed by the teachers including item difficulty, the size of circuit and program complexity of the right choice. Too simple is not easy to stimulate students' creativity, too complex to make students have the fear is not conducive to the students subjective initiative into full play. (2) Analysis and preparation of the project. At this stage, teachers teach students the basic flow of electronic project development, combined with the project introduced its contents in each of stage contains, told students to requirements of experiments, and then tell the students the project need to use the knowledge to ask the students to collect relevant data. (3) The design of the project development. The stages is the main part of the project teaching method, teachers monitor the progress of each student projects, and provide help and guidance at any time, teacher can timely solve any problems encountered in the process of project students to ensure the project progress of each student. (4) Project evaluation and summary. Design after the completion of the project, need to evaluate each student's design and summary, one of the most basic requirement is to reach the front of the proposed indicators [6].

\section{The Review of the Education Reform}

Build the basis of the open teaching mode. Teaching of the institutions of higher learning is the concept of a literal, it is more than just undergraduate teaching and graduate teaching, it should include the teaching and scientific research, the three interdependent, be short of one cannot. Discipline teacher only standing in front, have double research achievements of theory and application, may be the most advanced ideas and methods of penetration into teaching, and form a new teaching system. To do this, they should break through the traditional teaching the relatively closed space, explore the open teaching and research combining, multimedia combination, courses and comprehensive training of new pattern, so as to complete the basic course of relocation.

Attach the great importance to the construction of modern teaching infrastructure in support of the researchoriented teaching mode, the implementation of innovative education. Increased funding for teaching software and hardware facilities, the modern teaching condition greatly improvement. With this improvement accordingly management system, improve efficiency of the equipment operation. Each project is open emphasizes on the students' teaching experiment, open across departments, and developing the experimental research, design, style, to meet the needs of curriculum reform, provide the conditions of students in curriculum research. In the construction of modern teaching environment at the same time, the universities should actively applying modern education technology [7-8].

\section{The Science and Engineering Related Education}

Electronic technology is important technical basic course of colleges and the universities, most colleges and universities will be covered in more professional, the students in the process of electronic technology course, get involved in the electronic technology theory and skills, not only can use the application ability of students, development ability and the comprehensive utilization ability, it also can improve the students' innovation consciousness, rich professional courses. The traditional teaching methods can't satisfy comprehensive development of modern teaching and it can't give students fully thinking space. Students should be in the process of electronic technology and knowledge, active thinking, teachers should stimulate students' interest in learning, from several aspects to cultivate the students' innovation ability.

Cross integration of the science and engineering teaching, not only conforms to the need of talent cultivation and development of science and technology, but also to inevitable trend of construction of high level comprehensive university, comprehensive colleges and universities should not only on the subject setting, more should be embodied in personnel training, scientific research and the subject construction. In the teaching of colleges and universities, to the spirit of combination of technology and the liberal arts penetration; on the scientific research and discipline construction, to organize a combination of interdisciplinary and multidisciplinary cooperation. Teaching content should be able to reflect school and teachers of scientific research academic opinions and academic characteristics. Teaching methods should be heuristic, attract is not only a graduate student, and the undergraduate students to participate in scientific research and academic activities. 


\section{STEM 家}

Science, Technology, Engineering, and Mathematics (STEM)

Scientists are more likely to have a graduate degree than other STEM workers

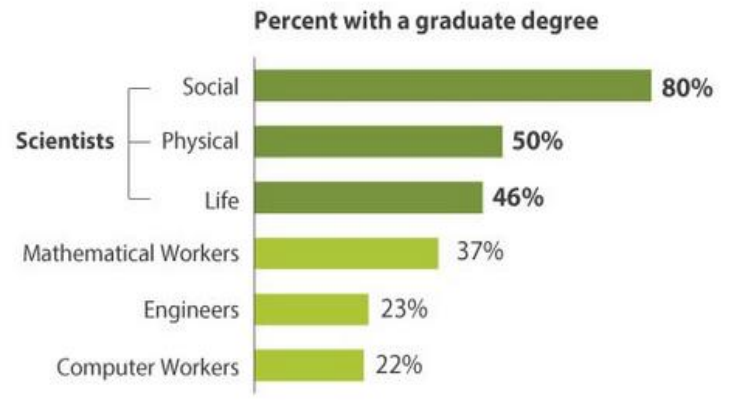

Figure 2. The Working Orientation of the Science and Engineering Majored Students

Schools are to form a lively, positive, and effective scientific research environment, facilitate the cultivation of students' innovative ability. Innovation is the soul of scientific research, colleges and the universities should actively undertake national or the regional economic construction and social development of the subject, in the process to solve the problem have their own intellectual property rights innovation. Management is a science as university management is an important science. Must strengthen the research of higher education management, the management of colleges and universities should encourage mechanism of teaching and scientific research to promote the healthy development of the school. In the teaching process, teachers and students form a kind of interactive as the heuristic method of teaching should pay attention to arouse the enthusiasm of students' learning. Establish the heuristic teaching procedure, set the curriculum knowledge, for knowledge, through interaction with students let students understand the role of each part, application situation, and problems. Heuristic teaching can improve student learning enthusiasm and initiative, but also promote the teachers' overall teaching level [912].

\section{CONCLUSIONS}

In this paper, we conduct research on the novel education pattern for science and engineering classes based on experiment and the interactive teaching method. University teaching reform is the basic principle of the teaching academic reform should be consistent with the school's scientific research mission, namely, encourage the use of academic and teaching reform on the basis of the research methods. University's primary goal is to provide high quality undergraduate and graduate education, the teaching principle of innovation to promote the colleges to form research guidance teaching. The executor of the teacher's teaching behavior is the important part of the teaching activities, teachers' teaching ideas and the methods directly affect the teaching quality. Field is the custom to the external environment, school, apparently, is one of many fields. School teachers in field of life, the classroom teaching behavior must be subject to the rules of the school field. Our research proposes the novel perspective for the college education which is meaningful. In the future, more in-depth analysis will be conducted for verifying the effectiveness of our proposed method.

\section{ACKNOWLEDGMENT}

This research was financially supported by the 2015 Research Project of Higher Education Reform in Shaanxi (15BY126) and the 2015 Teaching Reform Research Planning Project of Xijing University (JGGH1511).

\section{REFERENCES}

[1] Silverman, Howard, et al. "A Novel Approach to Supporting Relationship-Centered Care through Electronic Health Record Ergonomic Training in Preclerkship Medical Education," Academic Medicine, vol. 89, no.9, pp. 1230-1234, 2014.

[2] Morimoto, R., et al. "Impaired force-frequency relation pattern as a novel prognostic predictor in patients with hypertrophic cardiomyopathy," European Heart Journal, vol. 34. suppl 1, pp. 867 2013.

[3] Schachat, Sandra R., Jeffrey C. Oliver, and Antónia Monteiro "Nymphalid eyespots are co-opted to novel wing locations following a similar pattern in independent lineages," BMC evolutionary biology, vol. 15, no. 1, pp. 20, 2015.

[4] Barbu, Tudor, "Novel Pattern-based Fingerprint Recognition Technique Using 2D Wavelet Decomposition," In Proceedings of the 3rd International Conference for the Applied Mathematics and Informatics (AMATHI'12), Montreux, Switzerland. 2012.

[5] Liaghat, Alireza, and Farshad Rassaei, "A novel algorithm for inverse halftoning using LUT approach and pattern labeling," In Business Engineering and Industrial Applications Colloquium (BEIAC), 2012 IEEE, pp. 167-171. IEEE, 2012.

[6] Liqin, $\mathrm{Xu}$, Zhong Jin, and Wang Chonghua, "A novel microstrip antenna with double notches," International Conference on Advanced Information Engineering and Education Science. 2013.

[7] Yumei, Qi, Wang Shengfeng, and Zhang Ziqi, "Application of interactive teaching to the course of Community Nursing," Journal of Nursing Science, vol. 7 035, 2012.

[8] Harrison, Neil, "Using the interactive whiteboard to scaffold a metalanguage: Teaching higher order thinking skills in preservice teacher education," Australasian Journal of Educational Technology, vol. 29, no. 1, 2013.

[9] Zhou, Quan, Ji Cheng Liu, Chao Liu, and Jian Hong Yao, "The Cultivation of Comprehensive Ability of Students under Interactive Network Teaching Environment for Automation," In Advanced Materials Research, vol. 926, pp. 4645-4648, 2014.

[10] Sweeney, Trudy, "Understanding the use of interactive whiteboards in primary science," Australasian Journal of Educational Technology, vol. 29, no. 2, 2013.

[11] Milovanovic, Marina, Jasmina Obradovic, and Aleksandar Milajic, "Application of Interactive Multimedia Tools in Teaching Mathematics--Examples of Lessons from Geometry," Turkish Online Journal of Educational Technology-TOJET, vol. 12, no. 1 pp. 19-31, 2013.

[12] Hennessy, Sara, Bjoern Haßler, and Riikka Hofmann, "Challenges and opportunities for teacher professional development in interactive use of technology in African schools," Technology, Pedagogy and Education, pp. 1-28, 2015. 